\title{
O ENSINO DE LÍNGUA INGLESA E A IDENTIDADE DE CLASSE SOCIAL: ALGUNS APONTAMENTOS
}

\section{ENGLISH TEACHING AND SOCIAL CLASS IDENTITIES: SOME PERSPECTIVES}

\author{
Gabriel Nascimento dos Santos* \\ Mariana Rosa Mastrella-de-Andrade **
}

\section{RESUMO}

O ensino da língua inglesa é um importante meio de construção de identidades sociais, dentre elas, a de classe (BLOCK, 2013). Entretanto, o número reduzido de investigações a esse respeito tem deixado de chamar a atenção para sua importância. Neste artigo, buscamos discutir por que a questão da identidade de classe social deve se tornar um aspecto relevante a ser considerado e investigado no ensino-aprendizagem de línguas, em especial aqui em relação à língua inglesa. Também buscamos, por meio da Análise de Discurso Crítica (FAIRCLOUGH, 2003, VAN DIJK, 2015), apresentar um recorte de uma pesquisa que investiga de que maneira o livro didático, um instrumento de autoridade na sala de aula (TÍLIO, 2010; CORACINI, 1999), constrói identidades de classe social e quais os significados dessas identidades. Os resultados reforçam a premissa de que o ensino de inglês é, em grande medida, espaço de construção de identidades de classe, contribuindo para a manutenção de exclusões e desigualdades.

Palavras-chave: Identidade; classe social; ensino de inglês.

\section{ABSTRACT}

English language teaching is an important means of constructing social identities, and among those identities we have social class identity (BLOCK, 2013). However, the small number of studies in this regard has failed to draw attention to its importance. In this article, we discuss why the issue of social class identity should become an important aspect to be considered and investigated in the language teaching-learning, especially hereafter in relation to the English language. We also seek, through the Critical Discourse Analysis (FAIRCLOUGH, 2003; VAN DIJK, 2015), present a part of a research that investigates how the English language coursebook, an authority instrument in the classroom (TILIO, 2010; CORACINI , 1999), constructs social class identities and the meanings of these identities. The results reinforce the premise that English language teaching is largely a locus for social class identities, contributing to the maintenance of exclusions and inequalities. Keywords: Identity; social class; English language learning.

\footnotetext{
* Universidade de São Paulo, São Paulo (SP), Brasil. gabrielnasciment.eagle@hotmail.com

** Universidade de Brasília, Brasília (DF), Brasil. marianamastrella@gmail.com
} 


\section{INTRODUÇÃO}

"Nowadays it is fashionable to talk about race or gender; the uncool subject is class" (hooks, 2000).

"Quem pode aprender inglês?" tem sido uma pergunta discutida por alguns autores nas últimas décadas (ASSIS-PETERSON; COX, 2007; PAVLENKO; NORTON, 2007; PENNYCOOK, 2001; AUTORA, 2011; NORTON; KAMAL, 2003). Apesar de a resposta "todos/as os/as cidadãs/ãos no mundo" ser rapidamente apontada, pesquisas têm mostrado que o acesso à educação em línguas, em especial a língua inglesa, nem sempre é tratado como direito de todos os indivíduos e todas as comunidades. $\mathrm{O}$ inglês, por exemplo, língua que exerce um papel hegemônico no mundo contemporâneo (RAJAGOPALAN, 2011), já há um tempo tem sido apontado como um bem simbólico no Brasil (MOITA LOPES, 2005), ao qual tem acesso (em grande parte) quem pode por ele pagar (GIMENEZ, 1999). Presente nas dificuldades que emperram o acesso, portanto, estão questões de classe social, ou seja, o acesso a bens e consumo na sociedade globalizada não se dá de forma igualitária.

Fortemente enfatizada na modernidade, cantada, inspirando romance e poesia durante séculos, a "promessa da igualdade", da possibilidade de que os indivíduos vivam vidas sem disparidades no que se refere a saúde, moradia, educação, lazer, dentre outros aspectos, é hoje facilmente refutada, segundo Santos (1999b, p. 198). Para o autor, é possível encontrar em todos os cantos do planeta dados que mostram como as desigualdades imperam, como as possibilidades de aquisição são díspares entre os grupos de indivíduos e como uma pequena parcela da população mundial acumula riquezas enquanto uma grande maioria se torna cada vez mais pobre e com menores condições de dignidade humana.

De acordo com Bourdieu e Passeron (2009), o sistema educacional e escolar é responsável por manter muitas das desigualdades da sociedade, perpetuando e reproduzindo discursos e relações que legitimam as diferenças sociais fora das salas de aula. Estudos que discutem sobre o insucesso do ensino de inglês no Brasil têm enfatizado que a escola pública, não cumprindo com a missão de ensinar a língua inglesa, contribui para que classes menos favorecidas deixem de se tornar usuárias dessa língua, reproduzindo, assim, a ordem econômica e social vigentes (COX $;$ ASSIS-PETERSON, 2008, p. 36). Pode-se entender, a partir dos estudos das autoras citadas, que, para classes menos privilegiadas, o inglês como língua estrangeira, ainda que direito assegurado na Lei de Diretrizes e Bases (BRASIL,

1 "Atualmente está na moda falar de raça ou gênero; a questão desagradável é classe" (hooks, 2000). 
1997), tem sido negado. Entretanto, de acordo com Norton e Toohey (2011), estudos com foco em identidades de classe social, que analisem desigualdades no acesso à educação em línguas, precisam ainda ser mais enfatizados tendo em vista $\mathrm{o}$ contexto de iniquidades que a globalização nos apresenta. Nesse sentido, temos aqui dois objetivos: em primeiro lugar, discutir por que a questão da identidade de classe social deve se tornar um aspecto relevante a ser considerado e investigado no ensinoaprendizagem de línguas, em especial aqui em relação à língua inglesa. Em segundo lugar, pretendemos, a partir do suporte que a resposta para o primeiro objetivo nos dá, apresentar um recorte de uma pesquisa que investiga de que maneira o livro didático, um instrumento de autoridade na sala de aula (TÍLIO, 2010; CORACINI, 1999), constrói identidades de classe social, quais os significados dessas identidades e como elas podem participar do processo de exclusões no ensino de inglês.

Sendo esses nossos objetivos, apresentamos a seguir perspectivas teóricas sobre classe social na contemporaneidade, sobre como identidades são construídas e como identidades de classe social são entendidas na área da Linguística Aplicada. Discutimos algumas pesquisas que enfatizam como as identidades de classe social têm sido abordadas em relação ao ensino de línguas e como elas se tornam então relevantes para o cenário de globalização e de pós-modernidade no qual nos inserimos. Em nossa parte de análise, apresentamos um recorte de um livro didático de inglês, mostrando a maneira como identidades de classe social são construídas e naturalizam as desigualdades.

\section{MODERNIDADE: CUMPRIMENTO HISTÓRICO E RUPTURAS}

A segunda metade do século XX trouxe consigo uma série de transformações conjunturais e estruturantes que invocaram um conjunto de eventos que fazem ruir a agenda política da modernidade. Entre os eventos que norteiam esse contexto estão aquelas suscitadas a partir da Globalização, como é o caso do avanço tecnológico, da internacionalização da economia, da crise nas instituições políticas, dos novos movimentos sociais, da guinada neoliberal do capitalismo, que fazem surgir uma crise entre novas e velhas identidades (Santos, 1999a).

O ensino de língua inglesa não está alheio a essas transformações. Sendo elas um conjunto de reordenamentos na base social, o seu enraizamento e funcionamento está na prática social e, dentro dela, na prática discursiva, já que, como propõe Fairclough (1992), a prática discursiva está inserida na prática social. Ensinar novas línguas, portanto, e ensinar a língua inglesa, não se refere a simplesmente 
"transmitir" habilidades neutras de comunicação. Antes, insere-se como prática discursiva sobre que língua tem prestígio e confere prestígio a quem dela se apropria (PENNYCOOK, 2001).

Sendo assim, é possível afirmar, tomando como base Santos (2000) e Woodward (2000), que fenômenos como a globalização expandiram as desigualdades, ao mesmo tempo em que se deu a fragmentação da classe trabalhadora, a crise das organizações políticas, novos modos de representação social a partir do movimento estudantil da década de 60 e dos novos movimentos sociais a partir da década de 90, em que figuram cada vez mais a autorrepresentação, a competitividade e a individualidade. Todos esses movimentos históricos nos trazem, como propõe Block (2013), o retorno às discussões sobre o papel das classes sociais na atualidade e sua relação com questões de linguagem e com o ensino de línguas.

Como destaca Santos (1999a), o teste de cumprimento histórico da modernidade esgotou em excesso o cumprimento de alguns pontos e deixou de cumprir algumas promessas. Essas promessas a que se refere o autor são aquelas fundadas a partir da lógica do liberalismo, que tinham a igualdade e a fraternidade como elementos adjuntos. O sufrágio universal, o livre comércio e a emancipação do sujeito são algumas dessas promessas não cumpridas pela modernidade. Entretanto, podemos destacar como pontos que foram cumpridos em excesso os projetos econômicos nela identificados e executados e, como promessas não cumpridas pelo projeto da modernidade, a conquista de uma sociedade mediada pela razão, pela igualdade, liberdade e fraternidade. Sendo assim, é preciso discutir, a partir do cumprimento excessivo e do não cumprimento de promessas trazidas com a modernidade, quais rupturas nos levam às críticas da pós-modernidade. Em primeiro lugar, partindo do fenômeno mais abundante da modernidade: o sistema capitalista.

Retomando o que foi analisado por Santos (1999a), podemos reivindicar que o capitalismo é o fenômeno central da modernidade, em que os meios sociais de produção são revolucionados, todo o espectro de produção é concentrado nas mãos da burguesia agora fortalecida e o trabalho individual é alienado a fim de gerar lucro (MARX \& ENGELS, 2007). É ainda o filósofo Karl Marx que apresenta as principais críticas, no interior da Economia política, às mazelas socioeconômicas herdadas pela consolidação da modernidade, e o capitalismo como seu principal fenômeno.

Assim, pergunta-se: é possível definir a pós-modernidade em termos sistemáticos? É o que desmitifica Hall (1999) ao tratar a pós-modernidade através da identidade cultural, pois, se há pós-modernidade, a identidade cultural instaurada 
por ela é completamente o questionamento de uma ordem de definição herdada do discurso da modernidade. Esses questionamentos servem para guiar nossa discussão, mas não receberão respostas diretas. Nos cãs da atualidade, não há identidades fixas e possibilidade para definição da pós-modernidade de modo sistemático. Sendo assim, a identidade se apresenta como ambivalente, desterritorializada, não fixa, provisória, como discutiremos a seguir na próxima subseção. Produto de uma série de eventos históricos que fazem cair por terra os grandes modelos seculares, o discurso da pós-modernidade ganha espaço onde falta certeza.

Assim, para discutir a pós-modernidade, é preciso discutir qual o novo papel do Estado:

Como o Estado não mais promete ou deseja agir como plenipotenciário da razão e mestres de obras da sociedade racional; ${ }_{i}$ como as pranchetas no escritório da boa sociedade estão em processo de ser eliminadas; e como a variada multidão de conselheiros, intérpretes e assessores assume cada vez mais as tarefas previamente reservadas aos legisladores, não é de surpreender que os críticos que desejavam ser instrumentais na atividade de emancipação lamentem sua privação. Não apenas o suposto veículo - e, simultaneamente, o alvo da luta pela libertação - está se esfacelando; o dilema central, constitutivo, da teoria crítica, do próprio eixo em torno do qual girava o discurso crítico, dificilmente sobreviverá ao desparecimento do veículo. (BAUMAN, 2001, p. 64)

Através da crítica acerca de como se chega à pós-modernidade, Bauman (2001) e Santos (1999a) apresentam soluções parecidas. Bauman (2001) destaca que o Estado não desenvolve mais o papel de plenipotenciário da razão, pelas razões que Santos (1999a) desenvolve ao analisar o papel central do capitalismo na transição da modernidade para a pós-modernidade. Assim, Santos (1999a) destaca que o avanço do capitalismo esgotou o projeto político da modernidade e fez com que entrasse em cena uma crise de regulação, em que a subjetividade e a emancipação emergentes do projeto político da modernidade são colocadas em xeque.

A fim de narrar a transição do moderno para o pós-moderno, e tomando o capitalismo como fenômeno central, Santos (1999a) identifica três períodos como norteadores. O primeiro período é o do capitalismo liberal, em que se buscou a harmonia entre os princípios, no nível da regulação, do Estado, do mercado e da comunidade, sem êxito. O não êxito da harmonia do projeto proposto pelo capitalismo liberal se deu, segundo o autor, por causa do desenvolvimento do princípio do mercado em detrimento do Estado e da comunidade. Marx e Engels (2007) também alertam para o perigo do encolhimento do espaço público através do alargamento do princípio do mercado não regulado pelo Estado. Com o desenvolvimento político do capitalismo liberal, o ideário representado em laissez 
faire ${ }^{2}$ transformou o princípio da comunidade em dois: a sociedade, como lugar de competitividade de interesses particulares e o indivíduo, como livre e igual e elemento fundamental da sociedade civil.

O segundo período é o do capitalismo estável ou organizado. É aquele em que modificações são feitas a fim de tentar manter o projeto político do capitalismo na modernidade. Nele as relações entre Estado, mercado e comunidade se tornam mais harmoniosas, de modo que ocorre uma expansão gradual do proletariado, do sufrágio universal e dos direitos trabalhistas. São consequências das políticas sociais desse segundo período o Estado de bem-estar social ou Estado-providência, em que o Estado passa, no nível da regulação, a garantir à comunidade os direitos e recursos que garantiu ao mercado no primeiro período. Segundo o autor, é nesse período que o projeto da modernidade cumpre-se em excesso e excede todas as expectativas.

O terceiro período é aquele que começa na década de 70 e se estende até os dias de hoje, com a última crise do capitalismo. Santos (1999a) o conceitua como fase do capitalismo desorganizado. Nesse período, o princípio do mercado voltou a se estender, dessa vez com "pujanças sem precedentes" (SANTOS, 1999a, p. 87). Esse princípio cresceu de volta tão abundante que colonizou "tanto o princípio do Estado, como um princípio da comunidade - um processo levado ao extremo pelo credo neoliberal" (SANTOS, 1999a, p. 87). No plano econômico, acontece a internacionalização das economias através das políticas da globalização, levadas a cabo pelas multinacionais, a crise de representação da classe trabalhadora pelos sindicatos, a flexibilização e automatização dos processos produtivos, que

combinadas com o embaratecimento dos transportes, permitem a industrialização dependente do terceiro mundo e destroem a configuração espacial do aparelho produtivo nos países centrais com a descaracterização das regiões, a emergência de novos dinamismos locais, a ruralização da indústria, a desindustrialização, a subcontratação internacional etc., etc.; a expansão extensiva do mercado corre paralela à sua expansão intensiva com a crescente diferenciação dos produtos de consumo, um certo abandono da grande produção em massa com o objetivo de promover a particularização dos gostos e o aumento das escolhas, finalmente, a mercadorização e a digitalização da informação abrem perspectivas quase infinitas à reprodução alargada do capital. (SANTOS, 1999, p. 88)

Para Santos (2000), confirmando a forma agressiva de alargamento do projeto político do capitalismo em seu terceiro período descrito acima, a globalização é o fenômeno que se impôs ao mundo como um novo paradigma de internacionalização

2 Deixa fazer, em francês, do par representado pelo projeto liberal: Laissez faire-Laissez passer: Deixe fazer, deixe passar, representando o liberalismo comercial e econômico. 
do sistema capitalista. O projeto político em andamento desse terceiro período do capitalismo garantiu que as injustiças sociais aumentassem na contemporaneidade, nos levando a dilemas como o avanço da concentração de renda, do capital especulativo e a globalização das desigualdades.

\section{PRÁTICAS DE CONSTRUÇÃO IDENTITÁRIA}

Falar de identidades é falar de quem e do que somos (BLOMMAERT, 2005) a partir de uma concepção de língua e linguagem que vai além da ideia de simples descrição de realidades pré-concebidas. Nessa concepção, segundo a qual fazer uso de linguagem é formar - realizar, operar - e transformar o mundo social (FAIRCLOUGH,1992), uma das coisas que fazemos na linguagem é a própria formação de quem nós somos, isto é, fazemos a nós mesmos.

Woodward (2000) apresenta uma ideia de identidade construída em sistemas classificatórios sempre transitórios entre o social e o discursivo, vinculando seu funcionamento a condições materiais e sociais. Para ela, as identidades podem ser construídas a partir de elementos também simbólicos (como a roupa que se usa). Silva (2000) destaca a importância fundamental da diferença para a significação da identidade. Ao contrário do que por vezes se pode imaginar, a identidade não é o oposto da diferença, mas construída por meio dela, sendo, portanto, relacional. As oposições fundamentais, os jogos de sentido, as tentativas de inclusão e exclusão, o jogo nós/eles, funcionam como binarismos que fazem operar a reivindicação de identidades. Hall (2000) chama a atenção para o papel da linguagem para a reivindicação e representação das identidades, reafirmando o papel do discurso:

É precisamente porque as identidades são construídas dentro e não fora do discurso que nós precisamos compreendê-las como produzidas em locais históricos e institucionais específicos, no interior de formações e práticas discursivas específicas, por estratégias e iniciativas específicas. (HALL, 2000, p. 109)

Nessa perspectiva, buscamos aqui chamar essa dinâmica de construção de identidades de práticas identitárias, considerando que as identidades não são fixas, imutáveis, mas social e linguisticamente construídas e, assim, dinâmicas, fluidas, contextuais. Fairclough (1992) também reconhece que a identidade é construída pela linguagem, não sendo, portanto, um dado da natureza, mas o resultado de uma política de representação estabelecida pela linguagem, comportando-se como uma prática discursiva, a qual se enquadra numa dada prática social. A identidade, assim, 
tem significados que não são naturais e fixos, mas provisórios, como se dá com a própria linguagem.

Compreendendo dessa forma o papel da linguagem para as práticas identitárias, buscamos discutir, a seguir, identidades de classe social.

\section{PARA UM CONCEITO DE CLASSE SOCIAL}

Não há como tratar de classes sociais sem retomar os trabalhos de Karl Marx. Mesmo que, segundo Block (2013), Marx não tenha conceituado classes sociais propriamente, mas apenas descrito sua atuação, o conceito faz-se importante para as ciências sociais.

Segundo Marx (2000) e Marx e Engels (2005, 2007, 2008), o capitalismo, sendo o maior fenômeno da modernidade, fez surgir duas principais classes: a burguesia e o proletariado. É importante destacar que, como nos chama a atenção Block (2013), Karl Marx não excluía a possibilidade de outras classes. Sua escolha pela descrição de duas principais classes se deve ao fato de que a revolução industrial teria colocado como sua principal classe a burguesia que, para ter seus objetivos seculares resolvidos, criou a única classe que, segundo ele, poderia ser verdadeiramente revolucionária: o proletariado.

A mudança radical do capitalismo após a Segunda Guerra permitiu a formulação de uma série de estratégias que tinham como mote a descentralização do papel do Estado, levando ao enfraquecimento do Estado de bem-estar social ou Estado-providência. ${ }^{3}$ Um dos fenômenos principais que seguem é a fragmentação da classe trabalhadora a partir do corte de direitos trabalhistas. Fragmentada, a classe trabalhadora perde seus referenciais de representação. Assim:

\footnotetext{
Em primeiro lugar, esta fragmentação do objeto da produção é também necessariamente a fragmentação do seu sujeito. Em consequência da racionalização do processo de trabalho, as propriedades e particularidades humanas do trabalhador aparecem cada vez mais como simples fontes de erro, racionalmente calculado de antemão, destas leis parciais abstractas. O homem não aparece, nem objectivamente, nem do seu comportamento, em relação ao processo de trabalho como verdadeiro portador deste processo, está incorporado como parte mecanizada num sistema mecânico que encontra pela frente, acabado e a funcionar em total independência relativamente a ele, a cujas leis têm de se submeter. (LUKÁCS, 1974, p.103, grifos do autor)
}

\footnotetext{
3 Para esses dois termos, convergindo no mesmo fenômeno, utilizamos Santos (1999) e Chauí (2006) para conceituar. O Estado de bem-estar social ou Estado-providência pode ser interpretado como um conjunto de mudanças que, no início do século XX, são implantadas em países capitalistas avançados de modo a garantir direitos fundamentais que a classe trabalhadora pautou em todo o século XIX. Fazem parte do Estado de bem-estar social ou Estado-providência os direitos trabalhistas como as férias, redução da jornada trabalhista, décimo terceiro salário, etc.
} 
A partir daí, estando o trabalhador já reificado ${ }^{4}$ e integrado ao processo de produção como mercadoria, ele próprio, os sindicatos e entidades classistas perdem o papel que tinham e novos movimentos sociais, organizados de forma horizontal e se reivindicando para além das dicotomias capitalismo versus socialismo, direita versus esquerda, questionam, como menciona Woodward (2000), as grandes narrativas seculares.

No entanto, Block (2013) alerta quanto ao papel das classes sociais em um mundo repleto de assimetrias:

\begin{abstract}
$\mathrm{Na}$ verdade, as classes dominantes não apenas colocam a culpa pela atual crise econômica sobre as políticas que não vão longe o suficiente na liberalização da economia ou na falta de vigilância por parte das instituições (cujas políticas possibilitaram a crise), como elas também se recusam a enfrentar a sua responsabilidade pelo aumento da desigualdade e da desvantagem, tanto internacionalmente como intranacionalmente. E enquanto o público em geral, e na verdade a maioria dos acadêmicos também, não entender tudo o que está acontecendo nos níveis mais altos da economia mundial, eles não sabem o que veem e vivem em suas casas e seus bairros. E é a observação sobre o aumento da desigualdade e da desvantagem que tem levado muitos cientistas sociais a retornar à classe social como importantes lentes para se enxergar as sociedades contemporâneas e sua evolução em curso. (BLOCK, 2013, p. 12 ) ${ }^{5}$
\end{abstract}

Block (2013) explora, em sua obra Social Class and Applied Linguistics, aspectos de classe social no ensino de línguas, partindo de uma análise contextualizada de conjuntura de uma época, que vai desde a década de 70 até a atualidade, em que acontecem reformas estruturais neoliberais que ele chama de "liberalizantes", que aguçam as desigualdades e propõem novos enfrentamentos.

Ao conceituar classe social, Block (2013) retorna a Marx para criticar a ausência de uma conceituação clara. O linguista mostra como, porém, em Marx há uma estruturação sistemática do papel das classes sociais na história. Retornando a Weber e Durkheim, ele observa que a definição dos chamados grupos de status em Weber e grupos ocupacionais em Durkheim são classificações mais culturais do que

4 Termo que provém de Karl Marx, em alusão ao latim res=coisa, demonstrando que, pouco a pouco, o trabalhador é integrado à produção, tornando-se parte dele e, logo, se tornando capital, coisa, sendo coisificado.

5 Tradução nossa do original: "Indeed, not only do the ruling classes put the blame for the current economic crisis on policies that did not go far enough in the liberalization of the economy or on a lack of vigilance on the part of institutions (which through their policies they made possible), they also refuse to address their responsibility for the rise in inequality and disadvantage, both internationally and intranationally. And while the general public, and indeed most academics as well, do not understand everything that is going on at the highest levels of the world economy, they do know what they see and live in their homes and their neighborhoods. And it is the observation of rising inequality and disadvantage that has led many social scientists back to social class as an important lens through which to view contemporary societies and their ongoing evolution" (BLOCK, 2013, p. 12). 
sociais, de modo que não são explorados os funcionamentos e as condições dessas categorias na evolução do capitalismo, como o fez Marx.

Tanto Santos (1999) quanto Block (2013) alertam para as críticas feitas à determinação econômica em Marx. Santos (1999) adverte sobre o papel político que a modernidade propôs à luta de classes e Block (2013) destaca que, embora haja um tom determinístico que muitas vezes pareça negar a agência do sujeito, Marx usa o termo 'condicionar' ao invés de 'determinar'. Como linguista aplicado, a contribuição de Block (2013) é muito importante para entender que algumas ideias na obra de Marx precisam ser lidas nas entrelinhas. Assim:

Eu penso que vale a pena considerar como a classe social é retratada em Marx e Engels como experiência vivida explícita. Entretanto, eu começo com um ponto mais técnico, um ponto básico para entender a base econômica do capitalismo - a teoria do valor do trabalho segundo Marx - antes de passar para uma noção experiencial de alienação. (BLOCK, 2013, p 31 ) $^{6}$

É a partir da teoria do valor do trabalho em Marx que Block (2013) reivindica que sua conceituação de classe social adota a mesma desenvolvida por Marx, fortemente baseada no processo que produz capital através da relação de alienação da força de trabalho e subsunção do trabalhador na produção, de modo que este é condicionado a se sujeitar à função de assalariado. Como desenvolve Marx (2008), o valor pago ao trabalhador está colocado no valor de troca do produto, integrando a força de trabalho ao preço final da mercadoria, fixando um valor de troca em detrimento do valor de uso. Para tanto, Block (2013) entende classe social como uma noção econômica que agrega um grupo condicionado, mas não diretamente determinado, por fatores econômicos. Para o autor a base econômica não determina tudo que acontece na vida material, mas determina as forças que dirigem a vida material.

Outra teorização que aqui merece atenção são as análises de Pierre Bourdieu. Bastante influenciado pelo atual modo de produção capitalista, tendo a classe trabalhadora já sido fragmentada e, como adverte Santos (1999), perdido seu conteúdo político, Bourdieu $(1989 ; 1991)$ compreende a reprodução das classes

6 Tradução nossa do trecho: "This is a helpful breakdown of the key elements of Marxist class analysis, wherein there is a kind of cascade effect represented. The material condition and interests shape the consciousness of people, the social relations emergent in the practices of individuals and collectives and ultimately, the conflicts around class interests which arise when interests, consciousness, practices and social formations come together. And with this understanding of class relations in mind, I think it is a worthwhile to consider how social class is portrayed in Marx and Engels's publications as explicit lived experience. However, I start with a more technical point, one foundational to understanding the economic base of capitalism - Marx's labour theory of value before moving to the experiential notion of alienation" (BOCK, 2013, p. 31). 
sociais através do papel central da linguagem, na qual o símbolo em sua obra é usado não para negar o real, mas para delinear como as relações são mediadas na sociedade. Assim, Bourdieu (1987) critica o objetivismo secular de classe em si marxista ${ }^{7}$ e propõe a noção de grupos de status ou, antes, de classes consagradas por sua função, lógicas e costumes. Esses costumes, funções e comportamento são para o autor o capital simbólico e se conduzem pelo capital econômico.

A noção de classe em Bourdieu (1987), considerando também a perspectiva marxista de luta de classes, se insere no mundo contemporâneo levando em conta as manifestações de reestruturação do século XX. Para além dos demais autores, Bourdieu (1987) define classe social no enquadre do capital simbólico, das relações simbólicas, mediadas pela linguagem. Sendo a linguagem, ela própria, um capital simbólico, possibilita a consagração de categorias quase sempre reproduzidas na estrutura social.

Dessa forma, partindo das discussões anteriores, é preciso dizer que entendemos classe social como um grupamento condicionado por questões econômicas, em que indivíduos têm características socioeconômicas semelhantes (i.e. a proletarização, a subproletarização) ${ }^{8}$, com relações simbólicas (por exemplo o consumo) determinadas por razões econômicas (como a renda, acesso a serviços públicos fundamentais) e através da relação de antagonismo simbólico e econômico (e simbólico porque econômico) com outras classes sociais.

A diferença que vemos entre classes sociais e grupos de status como definidos por Bourdieu (1987) é que os grupos de status apenas cumprem o valor de classe no sentido da consagração de sua função, sendo que, em sua teoria, o autor se limita a falar de consagração sem fixar o processo do condicionamento econômico. Nesse sentido, nos filiamos à teoria desenvolvida por Bourdieu (1987) ao perceber que as classes não são grupamentos fechados em si, mas compostas de modo heterogêneo (inclusive com vários grupos de status em nosso entendimento), mas divergimos do lugar em que o autor coloca a base econômica da sociedade para o condicionamento das classes sociais. Sobre essa discussão, é preciso dizer que concordamos com Block (2013) que, em sua concepção de classe social, compreende que a base econômica não determina as classes sociais, mas as condiciona. Nesse caso, temos dois verbos que precisam ser mais bem delineados. Determinar é um termo problemático na

7 Em Marx, o termo é usado para delinear as discussões sobre consciência e funcionamento das classes sociais: "classe em si" foi a classificação de Marx das classes frente ao capitalismo e às forças produtivas, e "classe para si" seria a transformação da classe em si em uma classe verdadeiramente revolucionária e com consciência.

8 Para mais detalhes sobre o significado da diferença desses dois termos e a relação com o trabalho no Brasil, conferir Singer (1981). 
teoria marxista ortodoxa porque impõe que não existem relações de classe social fora da estrutura econômica, do que discordamos. As relações de classe estão dentro e fora da estrutura econômica, mas são diretamente condicionadas por ela, isto é, têm suas condições forjadas por ela. Ou seja, a classe social não está determinada, mas é condicionada nas forças produtivas do capital econômico (ou nas forças especulativas do capital financeiro). Por isso, o termo que melhor se aplicaria à relação entre classes sociais e a base econômica é condicionar (BLOCK, 2013), no sentido de prover e influenciar as condições. Tal condicionamento faz as classes funcionarem enquanto classes.

\section{IDENTIDADES DE CLASSE SOCIAL E ENSINO-APRENDIZAGEM DE INGLÊS}

Nesta seção, apresentamos algumas pesquisas, dentro e fora do Brasil, que enfocam classe social e ensino de línguas, algumas com foco em inglês especialmente. Nosso objetivo é mostrar como esses trabalhos apontam em consonância para o fato de que as identidades de classe estão intimamente imbricadas nos contextos de ensinar e aprender a língua inglesa e como, de maneira geral, o acesso à aprendizagem de inglês tem sido condicionado por questões de classe social, tendo acesso a ele quem tem melhores condições sócio-econômicas.

Em uma de suas pesquisas, Block (2013) discute o caso de Sílvia, uma estudante rica de 30 anos que estudou inglês em Barcelona, no final da década de 90. Durante sua pesquisa, o autor analisa a construção da identidade de classe social de Sílvia como pertencente à classe média alta, enfocando especialmente suas visões de classe em relação à colega Rosa, a quem atribui como "difícil de lidar" por causa do seu status social. Em suas análises, o autor enfoca como as questões de classe social produzem performances ${ }^{9}$ de sujeito e sugere que a identidade de classe social é construída no ensino-aprendizagem de línguas em uma relação de oposição com os demais sujeitos no mundo, pois os contextos sociais (com suas marcas simbólicas sobre de onde são, o que fazem, de onde vêm) de aprendizes e professores não são abstrações na sala de aula; antes, influenciam ativamente as interações. Com isso, o autor enfatiza que as identidades de classe social impactam de maneira importante o processo de ensinar e aprender línguas.

Darvin e Norton (2014) analisam o contexto de construção da identidade de classe social por imigrantes no Canadá. Um deles, Ayrton, mesmo na condição

9 Termo que se refere à maneira como as identidades são estilizadas na linguagem e nos discursos, produzindo sujeitos, conforme Butler (1994). 
de imigrante, é filho de uma família abastada, tem o pai empresário e estudou numa área rica de Vancouver. O outro, John, se mudou para o Canadá após passar anos longe da mãe, que havia ido trabalhar no Canadá. Os autores narram que John teve dificuldades na aquisição de inglês ligadas à sua condição social, pois o discurso do estudante marca sua posição marginalizada das Filipinas na hierarquia global de classe social. É preciso lembrar que, como Marx e Engels (2005) destacaram, a relação econômica entre países reproduz a hierarquia entre classes sociais. Nesse caso, a questão de classe social é colocada através da situação de imigração, em que estão em jogo identidades étnicas e identidades nacionais.

A pesquisa de Dias (2013) teve com objetivo entender como três alunos de classes sociais menos favorecidas no estado da Bahia constroem suas identidades ao aprender inglês. Os dados analisados mostram que classes menos favorecidas no Brasil têm menos acesso à aprendizagem de inglês, porém não menos desejo - a língua inglesa é desejada como meio de participação em práticas sociais diferentes e diferenciadoras para os sujeitos (como ser alguém capaz de ler certas obras, assistir e entender filmes, falar com estrangeiros, navegar com fluidez na internet, etc.), que atribuam mais prestígio aos falantes.

Santos (2013) discute como identidades de classe social são construídas em um livro didático adotado em uma instituição pública de ensino de línguas no Brasil. Suas análises apontam que o livro didático reproduz estereótipos no que se refere a aspectos como uso de serviços, lazer e profissões. Quanto ao uso de serviços, no livro há menção àqueles como saúde e atendimento médico, transporte, educação e serviço de creches para crianças apenas no setor privado; serviços para pessoas que devem e podem pagar. As pessoas que aparecem no livro fazendo uso desses serviços explicam o quanto pagam por eles, como o serviço é prestado, mas não há menção a como a esfera pública atende à população em relação aos mesmos aspectos, o que dá a entender que falantes de inglês não usufruem dos serviços sociais prestados pelo Estado, pois podem pagar por uma rede privada que os atenda (Santos, 2013, p. 164-165).

As análises de Rees (2009) mostram como nos livros didáticos de inglês as questões de classe social aparecem sem qualquer problematização, à medida que

diferentes personagens de várias partes do mundo, presentados no livro, que qualquer pessoa de qualquer lugar pode transitar pelo espaço da vida moderna. No entanto, é preciso dizer que não é um campo aberto de igualdade para todos, pois os personagens no LD que participam desse modo de vida são, em geral, jovens da classe média com profissões relativamente bem remuneradas. Assim, podem arcar com viagens, restaurantes e a compra dos objetos que acompanbam esse modo de vida, tais como CDs e roupas. $\mathrm{O}$ modo de vida moderno retratado no $L D$ é exclusivista, já que é restrito a um grupo seleto de pessoas. (REES, 2009, p. 169, ênfase nossa) 
Nessa mesma direção, Mastrella-de-Andrade (2014) analisa como as identidades de classe social e de raça são construídas em livros didáticos de língua inglesa. Destaca-se, nas análises, a manutenção da branquitude, isto é, da estandardização da raça branca como norma. Além disso, há uma abordagem elitizada de atividades de lazer, o que se dá a partir de experiências em lugares que requerem altos custos, como shoppings, boates, hotéis e cruzeiros, revelando que o LD apresenta, como padrão, as vivências culturais de classes sociais mais ricas.

Analisando a questão das classes sociais no ensino de línguas e na Linguística Aplicada nos Estados Unidos, Vandrick (2014) descreve formas como a educação nos Estados Unidos ecoam as diferenças entre classes quando, primeiramente, reúnem públicos com mesmo perfil socioeconômico, sinalizando, assim, as diferenças majoritárias entre classes sociais. Do mesmo modo, critica o desconhecimento dos professores de classe média sobre o sistema educacional, explicando que

Porque muitos professores são de classe média, e os sistemas educacionais enfatizam normas e valores de classe média, as experiências dos estudantes de classes populares ou baixas são sempre desvantajosas quando eles não entendem o sistema, ou são equivocadamente tratados como pessoas que não cumpriram as expectativas. (VANDRICK, 2014, p. 87) ${ }^{10}$

No contexto chinês, Gao (2014) investigou como seis estudantes chineses de classes privilegiadas negociaram suas identidades de classe durante um período de aprendizagem de inglês no Reino Unido. Como algumas de suas conclusões, destaca-se que o status socioeconômico dos estudantes mais privilegiados influencia suas oportunidades para aprender inglês e estruturar suas redes de amizade.

No México, López-Gopar e Sughrua (2014) analisaram a relação entre classes sociais no ensino de língua inglesa e colonialismo em Oaxaca. Os autores ressaltam em seu trabalho que as classes sociais precisam ser analisadas levando em conta seriamente não só a Economia... mas também a História ${ }^{11}$. Os autores concluem que o colonialismo se perpetua na região e que há um engajamento crítico entre as classes sociais e o ensino de inglês. Esse trabalho traz uma base muito importante para localizarmos a discussão sobre classes à luz da realidade pós-colonial, na qual a identidade de classe social é construída na condição de exploração colonial, em que tanto surgem identidades étnicas quanto identidades de classe social.

10 Tradução nossa do trecho: "Because many teachers are middle class, and educational systems emphasize middle-class norms and values, students from working-class or lower-class backgrounds are often disadvantaged when they do not understand the system, or are wrongly regarded as purposely flouting expectations".

11 Tradução minha do trecho: "tak[ing] not only economics seriously ... but also history". 
Duas considerações são importantes aqui sobre a relação entre identidades de classe social e ensino de inglês. Primeiramente, é preciso levar em conta que, para o contexto atual, as classes sociais não podem ser analisadas como fechadas em si $^{12}$. Desse modo, no ensino-aprendizagem de língua inglesa no Brasil, as classes sociais estarão relacionadas, indissociavelmente, a outras questões como étnico-raciais, de gênero, etc. Os dados dos últimos censos realizados pelo Estado brasileiro $^{13}$ e organizações análogas confirmam que a maioria mais pobre e sob condições miseráveis é, em geral, preta e parda, enquanto o contingente de mais ricos é composto de uma população branca. Esse fato é revelador para ponderar que os pesquisadores acima destacados não estão equivocados em suas análises de classe social no ensino de línguas. Os fatores de raça/etnia e gênero estão interligados com as questões de classe social nessa realidade, revelando que há interseccionalidade entre as identidades socialmente marcadas (BLOCK, 2013).

Em segundo lugar, chamamos a atenção para a necessidade de maior vinculação entre classe social e ensino de inglês no Brasil nos trabalhos da área de Linguística Aplicada, para fins de denúncia sobre como nossa sociedade tem estruturado e mantido a desigualdade nas, e através das, instituições educacionais. Voltando-se para a história do ensino de língua inglesa no Brasil, é preciso entender que a língua estrangeira só veio a ganhar um pouco mais de importância no currículo da escola pública a partir da reforma Capanema (LEFFA, 1999; VIDOTTI, 2012, 2013). Entretanto, a partir da Lei de Diretrizes e Bases de 1971, houve a desobrigação de oferta do ensino de língua estrangeira e o ensino de língua inglesa passou a ser ofertado cada vez mais por centros privados de idiomas. Por mais de vinte anos, a desobrigação do ensino de língua estrangeira na escola pública serviu para garantir o ensino dessas línguas a classes mais privilegiadas e ainda hoje o Brasil não possui uma política de ensino de línguas estrangeiras (incluindo aqui não apenas o inglês) que torne o acesso à aprendizagem justo e democrático.

Essas questões começam a responder por que a identidade de classe social nos importa enquanto pesquisadores e professores de língua inglesa. Compreendemos que, por ainda estar elitizado, o ensino de língua inglesa, tomado como capital simbólico e cultural, ainda é garantido apenas aos filhos de classes mais abastadas. Essas comparações sugerem que há questões de classe social que impactam o ensino-

12 Da mesma forma como as identidades não são totalizantes, isto é, identidades de classe são, ao mesmo tempo, identidades de raça, de gênero, de idade, etc. (BLOMMAERT, 2005, PENNYCOOK, 2001).

13 Para uma análise mais aprofundada da relação entre classe sociais e populações étnicas no Brasil, conferir Censo de 2010 realizado pelo IBGE em http://censo2010.ibge.gov.br/. 
aprendizagem de língua inglesa e que, portanto, identidades de classe social são aí construídas e representadas. Nesse contexto, apresentamos a seguir um recorte de análise sobre a maneira como identidades de classe social são construídas em um livro didático de inglês adotado em uma instituição pública no DF.

\section{METODOLOGIA DE ANÁLISE}

A fim de viabilizar nossas investigações de como identidades de classe são construídas e reproduzidas no livro didático de inglês, buscamos analisar um texto da coleção de livros didáticos American English File, da editora Oxford. O motivo da escolha dessa coleção de livros se deve ao fato de ele ser um livro bastante adotado internacionalmente (conforme atesta TOMLINSON, 2010) e, no contexto brasileiro, ter sido adotado em algumas unidades dos Centros Interescolares de Línguas ${ }^{14}$ no Distrito Federal nos anos de 2012-2013.

Entendendo o livro didático como figura de autoridade (CORACINI, 1999) e espaço de construção de identidades (TÍLIO, 2010) na sala de aula, recorremos aqui à Análise de Discurso Crítica - ADC - (FAIRCLOUGH, 2003; RESENDE; RAMALHO, 2011) na condução das análises sobre os discursos do livro aqui investigado. Para fins de discussão neste artigo e por limitações de espaço, tomaremos aqui apenas um texto do livro didático. ${ }^{15}$ Seguindo na perspectiva da ADC, delimitaremos as categorias de storytelling - narrativização - e interdiscursividade para nossas análises.

De acordo com van Dijk (2015), a narrativização, ou o uso de histórias narradas, legitimamente passadas e, assim, legitimamente presentes, construindo sujeitos com poder de verdade através de suas histórias. Na narrativização, posições sociais são retratadas, naturalizadas, e há um reforço da ordem aparente das coisas.

A categoria da interdiscursividade, por sua vez, pode envolver diferentes discursos, mas também gêneros e estilos. A análise da interdiscursividade permite investigar "discursos articulados em textos e suas conexões com lutas hegemônicas mais amplas" (RAMALHO; RESENDE, 2011, p. 142). É nesse sentido que examinaremos a seguir o texto extraído do livro didático.

14 Os CILs, Centros Interescolares de Línguas, funcionam como institutos de línguas que oferecem inglês, francês e espanhol para alunos de escolas públicas do DF.

15 Uma análise mais aprofundada do livro didático pode ser conferida em Nascimento (2016). 


\section{IDENTIDADES DE CLASSE SOCIAL NO LIVRO DIDÁTICO: MARCAS DE QUEM FALA E APRENDE INGLÊS}

Como já afirmamos anteriormente, traremos nesta seção um recorte de uma análise maior e mais ampla sobre construções identitárias de classe social no livro didático (NASCIMENTO, 2016). Para isso, apresentamos a seguir um texto retirado do Livro didático (doravante LD) American English File, volume 2, página 40:

\section{Zara}

Have you ever been to a Zara store?

You probably bave because it is one of the fastest-growing chains the world. The person bebind Zara is Amancio Ortega. He is the richest man in Spain, but very few people know bis face. There are only two official photographs of bim and be rarely gives interviews. Although be is a multimillionaire businessman, be doesn't look like one. He doesn't like wearing suits or ties and prefers to wear jeans and a shirt.

When be was young, be worked as a salesperson in a clotbing store, but be always dreamed of baving bis own business. In 1963 be started a small company that made women's pajamas. In 1975, at the age of 40, be opened bis first clotbing store in La Coruña, a city in northwest Spain, and named it Zara. Now you can find Zara Stores all over the world, from New York to Moscow to Singapore. So why is Zara so successful?

The main reason is that Zara reacts extremely quickly to the latest designer fasbions and produces clothes that are fashionable but inexpensive. Zara can make a new line of clothes in three weeks. Other companies normally take about nine months. The clothes also change from week to week, so customers keep coming back to see what's new. Zara produces 20,000 new designs a year, and none of them stay in stores for more than a month.

So if you've seen a new jacket or skirt that you like in a Zara store, burry up and buy it because it won't be there for long.

O texto retirado do LD apresenta informações sobre um estabelecimento comercial, uma loja de roupas e calçados internacionalmente conhecida. Logo abaixo do título do texto, o leitor é confrontado com uma pergunta: "você já esteve em uma loja Zara?", para a qual, no início do primeiro parágrafo, tem-se a resposta: "você provavelmente já esteve porque ela é uma das cadeias de loja que mais cresce no mundo". Identificamos no endereçamento direto do texto ao leitor, por meio de perguntas com o uso do pronome "you" - você, traços do discurso publicitário no texto do livro didático. O leitor é chamado a participar como interlocutor direto - é com ele que o texto interage. A identidade do leitor é construída à medida que o texto o interroga e responde por ele: o leitor "provavelmente já ouviu falar" da referida loja, pois ela está "no mundo todo".

Que tipo de leitor está sendo interrogado nesse caso? Quem é o leitor do texto que conhece a loja Zara? Um leitor consumidor, que talvez não conbeça a loja 
por consumir seus produtos, mas que, pelo menos, deveria reconbecê-la a fim de não ter uma resposta negativa a dar para a pergunta que abre o texto. Reconhecer a marca Zara, neste caso, segundo o texto, significa participar dos circuitos de moda e, principalmente, de desejo e de consumo por bens materiais que se traduzem em bens simbólicos de prestígio. Se as identidades, segundo Woodward (2000), são construídas simbolicamente (inclusive pelas roupas que se usa, como já foi dito), elas marcam o prestígio enquanto significado reconhecido e atribuído socialmente, o qual funciona para marcar e excluir de seu círculo aqueles que não podem participar das mesmas práticas de consumo.

Retomamos então o que afirma Hall (2000, p. 109) sobre a maneira como as identidades são construídas: "dentro e não fora do discurso", portanto construídas em locais "históricos e institucionais específicos". Nesse sentido, o discurso publicitário (inserido no discurso didático) no texto do livro didático contribui para a construção de identidades de classe social de quem fala inglês (pessoas que são apresentadas naturalmente como aquelas de quem o texto do livro didático fala) e fazem parte do universo dos que consomem o produto descrito - roupas da marca Zara. O mesmo discurso também contribui para a construção de identidades de quem aprende inglês e que então está lendo (consumindo) o texto porque utiliza o livro didático que o produz e faz circular.

Quanto à categoria da narrativização (storytelling), o texto conta a história de Amancio Ortega (mostrando também sua foto), fundador e dono das lojas Zara. No texto é dito que ele é "o homem mais rico da Espanha, mas muito poucas pessoas conhecem seu rosto (...) e ele raramente dá entrevistas. Embora ele seja um empresário multimilionário, ele não tem a aparência de um. Ele não gosta de usar ternos ou gravatas e prefere usar jeans e uma camisa".

A apresentação de Amancio Ortega, como se pode ver, é feita por meio de negações. De acordo com Fairclough (2003), a presença de um não indica o pressuposto de um sim, ou seja, aciona uma voz - um sim fora dito. Nesse sentido, apontamos no quadro a seguir os nãos e as vozes que eles acionam:

\begin{tabular}{|l|l|}
\hline Negação & Voz acionada (sim pressuposto) \\
\hline $\begin{array}{l}\text { "o homem mais rico da Espanha, mas muito } \\
\text { poucas pessoas conhecem seu rosto" - ele é um } \\
\text { bomem rico que não tem seu rosto conbecido }\end{array}$ & $\begin{array}{l}\text { Um homem rico, em geral, deveria (querer) ser } \\
\text { bastante conhecido }\end{array}$ \\
\hline $\begin{array}{l}\text { "ele raramente dá entrevistas" - ele não dá entrevista } \\
\text { frequentemente }\end{array}$ & $\begin{array}{l}\text { Um homem rico aparece em entrevistas, é } \\
\text { entrevistado, produz interesse em ser conhecido }\end{array}$ \\
\hline $\begin{array}{l}\text { "Embora ele seja um empresário } \\
\text { multimilionário, ele não tem a aparência de um" }\end{array}$ & $\begin{array}{l}\text { Um empresário multimilionário tem uma } \\
\text { aparência correspondente }\end{array}$ \\
\hline
\end{tabular}


"Ele não gosta de usar ternos ou gravatas e prefere usar jeans e uma camisa"

Ele não se importa em parecer multimilionário por meio de suas vestimentas, prefere um estilo mais simples.

Quais os significados da maneira como o dono da cadeia de lojas Zara é apresentado? Entendemos que essa apresentação inicial constrói a identidade do sujeito de quem se fala como alguém livre de ostentação. Essa identidade aparece como uma introdução à sua história, contada no parágrafo seguinte: "quando ele era jovem, ele trabalhava como vendedor em uma loja de roupa, mas sempre sonhou em ter seu próprio negócio. Em 1963 ele começou uma pequena empresa que fazia pijamas femininos. Em 1975, aos 40 anos, abriu sua primeira loja de roupas em La Coruña, uma cidade na Espanha, e a chamou de Zara. Agora você pode encontrar lojas Zara em todo o mundo".

De acordo com van Dijk (2015), as narrativas produzem legitimidade para as condições do presente. Essa afirmativa do autor nos é útil para entendermos por que a história pessoal do dono das lojas Zara ${ }^{16}$ é inserida no texto e, mais importante, que efeitos ela produz - ela contribui para legitimar e naturalizar a inserção da temática (consumo) no livro didático que a apresenta. A narrativa sobre a fundação da loja, sobre seu proprietário, naturaliza a entrada do mundo do consumo no livro didático, pois apresenta uma marca comercial como fruto de trabalho, de esforço, de um sujeito "real" que tinha um "sonho". Essa mesma narrativa também funciona para mascarar o aspecto publicitário do texto, forçando-o a tornar-se de possível interesse (por apresentar aspectos linguísticos na língua estrangeira) para aprendizes de inglês.

\section{ALGUMAS CONSIDERAÇÕES}

Neste artigo, buscamos discutir por que a questão da identidade de classe social deve se tornar objeto de relevância para investigações no ensino-aprendizagem de língua inglesa. Nossas argumentações mostram que, apesar de classe social não ser na contemporaneidade um conceito fechado em si mesmo, de fácil definição, vivemos em um mundo de enormes desigualdades, cuja estrutura e realidade o

16 Não podemos deixar de mencionar aqui as várias denúncias de manutenção de trabalho escravo e descumprimento de legislação trabalhista de que a marca ZARA tem sido acusada, que podem ser encontradas amplamente em diversos meios de comunicação (como exemplo, as informações disponíveis em: http://www1.folha.uol.com.br/mercado/2015/05/1627237-ministerio-do-trabalho-autua-zara-por-descumprir-compromisso.shtml. Acesso em 25/10/2016). 
ensino de línguas, aqui em especial o inglês, muitas vezes reproduz. Nesse sentido, deixar de lado as questões de classe social que estruturam e são reproduzidas no ensino da língua inglesa assume caráter de denúncia por transformações.

Nosso segundo objetivo - investigar de que maneira o livro didático constrói identidades de classe social, quais os significados dessas identidades e como elas podem participar do processo de exclusões no ensino de inglês - nos permite ressaltar que o livro didático dá, muitas vezes, mostras da maneira como o ensino de línguas participa na construção de falantes e aprendizes de inglês de classes sociais elitizadas, oferecendo parcas posições de identificação para alunos de classes menos privilegiadas, que em grande maioria habitam o chão das escolas públicas de nosso país, negando-lhes um lugar no diálogo em função de uma ausência de marcas identitárias locais.

\section{REFERÊNCIAS BIBLIOGRÁFICAS}

ASSIS-PETERSON, A. A.; COX, M. I. P. (2007). Inglês em tempos de globalização: para além de bem e mal. Calidoscópio, v. 5, n. 1, pp. 15-14, jan./abr.

BAKHTIN, M. M. (Mikhail Mikhailovich) (1997). Marxismo e filosofia da linguagem: Problemas fundamentais do metodo sociologico na ciencia da linguagem. 8.ed. São Paulo; Hucitec.

BLOCK, D. (2013). Social class in Applied Linguistics. Londres: Routledge.

BLOMMAERT, J. Discourse. A critical introduction. Cambridge: Cambridge University Press, 2005, p. 203-233.

BOURDIEU, P. (1987). A economia das trocas simbólicas. 2 ed. São Paulo, SP: Perspectiva.

BOURDIEU, P. Language and Symbolic Power. Cambridge: Polity Press, 1991.

BOURDIEU, Pierre. O poder simbólico. Lisboa: Difel, 1989.

BOURDIEU, Pierre. (2009), PASSERON, J. C. A reprodução: elementos para uma teoria do sistema do ensino. 2. ed. Petrópolis, RJ: Vozes.

BRASIL. Ministério da Educação e Cultura. Lei de Diretrizes e Bases da Educação. Rio de Janeiro: Casa Editorial Pargos, 1997.

BUTLER, J. (1994). Gender as Performance: An Interview with Judith Butler. Radical Philosophy. n. 67. Disponível em: <http://www.theory.org.uk/but-int1.htm>. Acesso em: 02/11/2015.

CHAUÍ, M. (2006) Simulacro e poder: uma análise da mídia. São Paulo: Fundação Perseu Abramo.

CORACINI, Maria José R. Faria. O livro didático nos discursos da Linguística Aplicada e da sala de aula. In: (Org.). Interpretação, autoria e legitimação do livro didático. Campinas: Pontes, 1999 
DARVIN, R.; NORTON, B. (2014). Social class, Identity, and migrant students. Journal of Language, Identity, and Education, v. 13, pp. 111-117.

DERRIDA, J. (1973). Gramatologia. São Paulo: Perspectiva.

DIAS, R. S. (2013). Desafios enfrentados por alunos de classes sociais menos favorecidas rumo à aprendizagem de inglês: uma questão de identidades. Dissertação (Mestrado) - Universidade de Brasília, Programa de Pós-Graduação em Linguística Aplicada, 161 p.

FAIRCLOUGH N. (1992). Discourse and social change. Cambridge: Polity press.

FAIRCLOUGH, N. Analysing Discourse: Textual Analysis for Social Research. London: Routledge, 2003.

FERREIRA, A.; CAMARGO, M. (2013) O racismo cordial no livro didático de língua inglesa aprovado pelo PNLD. Revista da ABPN. vol. 6, n. 12. pp. 177-202. 2013.

GAO, F. (2014). Social-Class Identity and English Learning: Studies of Chinese Learners. Journal of Language, Identity and Education, v. 13, n. 2, pp. 92-98.

HALL, S. (1999). A identidade cultural na pós-modernidade. 3. ed. Rio de Janeiro: DP \& A.

HALL, S. (2000). Quem precisa de identidade? In: Tomaz Tadeu da Silva. (Org.). Identidade e diferença. A perspectiva dos Estudos Culturais. 1ed.Petrópolis: Vozes, 2000.

LEFFA, V. (2013). Identidade e aprendizagem de línguas. In: SILVA, K. A.; DANIEL, F. G.; KANEKO-MARQUES, S. M.; SALOMÃO, A. C. B. (Org.). A formação de professores de linguas - Novos Olhares - Volume II. Campinas, Pontes Editores.

LEFFA, V. (1999). O ensino de línguas estrangeiras no contexto nacional. Contexturas, APLIESP, n. 4, pp. 13-24.

LÓPEZ-GOPAR, M. E.; SUGHRUA, W. (2014). Social Class in English Language Education in Oaxaca, Mexico. Journal of Language, Identity and Education, v. 13, n. 2, pp. 104-110.

LUKÁCS, G. (1974). História e consciência de classe: estudos de dialéctica marxista. Lisboa: Publicações Escorpião.

MARX, K. (2008). Contribuição à crítica da economia política. São Paulo: Expressão popular.

MARX, K. (2000). A origem do capital: a acumulação primitiva. São Paulo: Centauro.

MARX, K.; ENGELS, F. (2007). A ideologia alemã. 3. ed. Sao Paulo: Martins Fontes.

MARX, K.; ENGELS, F. (2005). Manifesto do partido comunista. São Paulo: M. Claret.

MASTRELLA-DE-ANDRADE, M. R.; RODRIGUES, J. A. A. (2014). Construção de identidades no livro didático de inglês: classe social, raça e o outro. In: Aparecida de Jesus Ferreira (Org, ). As políticas do livro didático e identidades sociais de raça, gênero, sexualidade e classe em livros didáticos. Campinas, SP: Pontes.

MOITA LOPES, L. P. (2005). Inglês no mundo contemporâneo: ampliando oportunidades sociais por meio da educação. Simpósio Inglês no Mundo Contemporâneo promovido pela International Research Foundation for English Language Education - TIRF. São Paulo.

NASCIMENTO, Gabriel. E a história não acabou... A representação da identidade de classe social no livro didático de língua inglesa. Dissertação (Mestrado em Linguística Aplicada). Brasília: 
Departamento de Línguas Estrangeiras e Tradução, Universidade de Brasília, 2016, $164 \mathrm{f}$.

NORTON, B. (1997). Language, identity, and the ownership of English. TESOL Quarterly, $31(3)$, pp. 409-429.

NORTON, B.; KAMAl, F. (2003). The imagined communities of English language learners in a Pakistani school. Journal of Language, Identity, and Education, 2(4), pp. 301-307.

NORTON, B.; KAMAl, F.; TOOHEY, K. (2011). Identity, language learning, and social change. Language Teaching, 44, 4, 412-446. (State-of-the-Art Article). Disponível em: $<$ http://educ.ubc.ca/faculty/norton/Norton\%20and\%20Toohey\%20Language\%20 Teaching\%202011.pdf $>$. Acesso em 26 maio 2015.

PENNYCOOK, A. Critical Applied Linguistics: a critical introduction. Mahwah, NJ: Lawrence Erlbaum Associates, 2001.

RAJAGOPALAN, K. (2001). The politics of language and the concept of linguistic identity. CAUCE, Revista de Filología y su Didáctica, n. 24, pp. 17-28.

RESENDE, V. M.; RAMALHO, V. Análise de discurso crítica. 2. ed. São Paulo: Contexto, 2011.

REES, D. K. The adventures of Robinson Crusoe e um livro didático: a hermenêutica do discurso do colonialismo. In: O livro didático de língua estrangeira: múltiplas perspectivas. Campinas, SP: Mercado de Letras, 2009, pp. 149-172.

SANTOS, B. de S. (1999a). Pela mão de Alice: o social e político na pós-modernidade. 5ed. São Paulo: Cortez.

SANTOS, B. de S. (1999b) Por que é tão difícil construir uma teoria crítica? Revista Crítica de Ciências Sociais, n. 54, pp. 197-215.

SANTOS, M. S. dos. (2013). A construção de identidades no livro didático de língua estrangeira: uma perspectiva crítica. Dissertação (Mestrado) - Universidade de Brasília, Programa de PósGraduação em Linguística Aplicada, $238 \mathrm{f}$.

SANTOS, M. (2000). Por uma outra globalização: do pensamento único à consciência universal. Rio de Janeiro: Record.

SILVA, T. T. (2000). A produção social da identidade e da diferença. In: Identidade e Diferença: a perspectiva dos Estudos Culturais. Petrópolis, RJ: Vozes.

SINGER, P. I. (1981). Dominação e desigualdade: estrutura de classes e repartição de renda no Brasil. Rio de Janeiro: Paz e Terra.

TILIO, R. C. A representação do mundo no livro didático de inglês como língua estrangeira: uma abordagem sócio-discursiva. The Especialist, v. 31, pp. 167-192, 2010.

TOMLINSON, B. English Language Learning Materials: A Critical Review. London, Continuum Books, 2010.

VANDRICK, S. (2014). The role of social class in English Language Education. Journal of Language, Identity and Education, v. 13, n. 2, pp. 85-92. 
VIDOTTI, J. J. V. (2012). Políticas linguísticas para o ensino de língua estrangeira no Brasil do século XIX, com ênfase na língua inglesa. Tese (Doutoramento em Letras- Estudos Linguísticos de Língua Inglesa). Universidade de São Paulo.

VIDOTTI, J. J. V. (2013). Política de língua estrangeira: o século XIX no Brasil. Saarbrucken: Verlag.

WOODWARD, K. (2000). Identidade e diferença: uma introdução teórica e conceitual. In: Tomaz Tadeu da Silva. (Org.). Identidade e diferença. A perspectiva dos Estudos Culturais. 1ed.Petrópolis: Vozes.

ZACHARIAS, N. T. (2010). Acknowledging Learner Multiple Identities in the EFL Classroom.K@ata,v.12,n.1,pp.26-41, Disponível em: http://puslit2.petra.ac.id/ ejournal/index.php/ing/article/viewFile/18022/17932. Acesso em 12/10/2011.

Recebido: 14/02/2016

Aceito: 24/10/2016 